\title{
Prevalence of the rs 1801282 \\ single nucleotide polymorphism of the PPARG gene in patients with metabolic syndrome
}

Renato Marano Rocha',2, Gustavo Barcelos Barra1,3, Érica Carine

Campos Caldas Rosa ${ }^{1,2}$, Érica Correa Garcia ${ }^{1,2}$, Angélica

Amorim Amato ${ }^{1,2,4}$, Monalisa Ferreira Azevedo ${ }^{1,2,4}$

\begin{abstract}
Objective:This study aimed to get the genotypic and allelic frequencies of rs1801282 in 179 volunteer donors and 154 patients with Metabolic syndrome (MetS) in Brasilia, Brazil and also examine the association with anthropometric, biochemical and hemodynamic variables in the latter group. MetS comprises a group of diseases resulting from insulin resistance, in-creased risk of type 2 diabetes and atherosclerotic cardiovascular disease. MetS is defined by the presence of increased visceral fat, atherogenic dyslipidemia (elevated triglycerides (TGL)), with decreased high density lipoprotein (HDL) and increased low density lipoprotein (LDL) levels, hypertension (BPH) and disturbances in glucose homeostasis representing a significant burden across the world due to the alarming increase in the incidence over the last decades besides their significant morbidity and mortality. Peroxisome proliferator activated receptor-gamma (PPAR $\gamma$ ) has been mentioned as a candidate gene for determining the risk of MetS. It is a member of the nuclear receptors superfamily and a ligand-activated transcription factor, which regulates the expression of genes involved in the network lipogenesis and adipogenesis, insulin sensitivity, energy balance, inflammation, angiogenesis and atherosclerosis. Among the PPARG genetic variants, single nucleotide polymorphism rs1801282 has been the most extensively studied one since it was first described by Yen and cols. in 1997. This polymorphism is characterized by the replacement of a proline (CCC) to an alanine (GCA) at codon 12 of exon $B$, due to the exchange of a cytosine with a guanine. The Ala allele frequency varies in different ethnic groups. Materials and methods: DNA was extracted using Chelex-100 method and determinations of genotypes were performed by allele-specific chain reaction. Results: The distribution of genotype frequency of the MetS group was not statistically different from the frequency in the donor population at large. In the first group, genotype frequency was CC to 0.869 and 0.103 for CG, while allelic frequencies were 0.948 for $\mathrm{C}$ and 0.052 for $\mathrm{G}$ allele. In the group of donors, the genotype and allele frequencies were 0.882 for CC, 0.117 to CG; and 0.941 to 0.059 for G and C, respectively. GG genotype was not found in any of the two groups. The genotype distribution and allele frequencies were in Hardy-Weinberg equilibrium. No marker could be detected from the analysis of anthropometric, biochemical and hemodynamic variables in the MetS group. Conclusion: Our data suggest that this polymorphism is not correlated with predisposition to MetS. The results obtained on a small sample of the population of Brasilia, corroborate the data reported in the literature on the prevalence of this polymorphism in PPAR in populations of different ethnic origins. Arch Endocrinol Metab. 2015;59(4):297-302
\end{abstract}

1 Programa de Pós-Graduação em Ciências da Saúde, Universidade de Brasília (UnB), Brasília, DF, Brazil

${ }^{2}$ Laboratório de Farmacologia Molecular, Faculdade de Ciências da Saúde, UnB, Brasília, DF, Brazil ${ }^{3}$ Unidade de Biologia Molecular, Instituto e Laboratório Sabin de Análises Clínicas, Brasília, DF, Brazil ${ }^{4}$ Hospital Universitário de Brasília, UnB, Brasília, DF, Brazil

Correspondence to: Renato Marano Rocha SHLS, Quadra 716, Conjunto L, Bloco 2, Salas 102/104 Centro Clínico Sul Asa Sul

70390-700 - Brasília, DF, Brazil remarano@ig.com.br

Received on July/6/2014 Accepted on Jan/12/2015 DOI: 10.1590/2359-3997000000086

\section{Keywords}

Single nucleotide polymorphism; metabolic syndrome; rs1801282

\section{INTRODUCTION}

$\mathrm{M}$ etabolic syndrome (MetS) comprises a group of related disorders stemming from insulin resistance and leading increased risk of type 2 diabetes and atherosclerotic cardiovascular disease. MetS is defined by the presence of increased visceral adiposity, atherogenic dyslipidemia [increased triglycerides (TGL), with decreased high-density lipoprotein (HDL), and increased low-density lipoprotein (LDL) cholesterol serum levels], hypertension (HBP), and disturbances in glucose homeostasis (1). It represents a significant worldwide burden due to the alarming increase in its incidence over the last decades, in addition to its significant morbidity and mortality (2).

Environmental and life-style changes are widely accepted as the key factors driving insulin resistance (3) and adiposity (4) and hence the current epidemics of MetS. However, they don't fully explain its occurrence and it is also believed that genetic factors play a major 
role in determining the predisposition to the syndrome. PPARG is a plausible candidate gene in determining the risk of MetS. It encodes peroxisome proliferator-activated receptor gamma (PPAR $\gamma)$, a member of the nuclear hormone receptor superfamily of ligand-activated transcription factor, which regulates the expression of network of genes involved in adipogenesis and lipogenesis, insulin sensitivity, energy balance, inflammation, angiogenesis and atherosclerosis (5).

Among the genetic variants of PPARG, the rs1801282 single nucleotide polymorphism has been the most extensively studied one since its first description by Yen and cols. in 1997 (6). This variant is characterized by the replacement of a proline (CCA) by an alanine (GCA) at codon 12 of exon $\mathrm{B}$, due to the exchange of a cytosine for a guanine. The Ala allele frequency ranges from 2 to $23 \%$ in different ethnic groups (7). Its frequency is low in Asian and African populations ( 1 to $3 \%)(6)$ and higher in Caucasians (20\%) (8-10). Deeb and cols. (11) were among the first researches to describe the functional implications of the Alla allele, by demonstrating that this variant displayed decreased binding affinity to the cognate promoter element and reduced ability to transactivate PPAR $\gamma$-responsive promoters. These findings suggested that the rs1801282 variant could contribute to the observed lower body mass index (BMI) and insulin sensitivity among the carriers of this polymorphism (11).

However, subsequent studies in different populations have proposed opposed conclusions. Some describe that the presence of polymorphisms confers a protective effect with respective do type 2 diabetes risk (12), whereas others indicate that it is associated with increased susceptibility to the disease $(8,13)$. There are also studies in which no association was found between this variant and the frequency of type 2 diabetes (14-16). To our knowledge, the association between the PPARG variant $r s 1801282$ and the risk of metabolic diseases has not been addressed in the Brazilian population. The aim of the present study was therefore to describe the genotypic and allelic frequency of the rs1801282 polymorphism among MetS patients from the University Hospital of Brasilia, in comparison with control subjects from Brasilia, Brazil. We also investigated whether the biochemical and anthropometric variables differed among MetS patients with the PPARG Ala variant when compared to those with the wild type Pro/Pro genotype.

\section{MATERIALS AND METHODS}

\section{Subjects}

All 154 MetS subjects enrolled in this study were from the population treated at the University Hospital of Brasilia. The patients were unrelated, aged over 45 years and had MetS in accordance to the National Cholesterol Education Program/Adult Treatment Panel III (NCEP/ATPIII) criteria (17). The 179 unrelated volunteers, of both sexes, aged over 45 , were blood donors from Blood Center Foundation of Brasilia. It was not possible to assess this population in all anthropometric and biochemical variables defined by NCEP ATPIII for MetS. However, the selection criteria helped us to exclude patients with diabetes (glycated hemoglobin < 6.5\%) (18), hypertension ( $\mathrm{BP}<$ $130 / 85 \mathrm{mmHg})(19)$ and obesity $(\mathrm{BMI}<30)(20)$. In both groups, the exclusion criteria were: patients who refused to participate in the study, under the age of 45 years and using hyperglycemic medications such as glucocorticoids. Written informed consent was obtained from each participant after a full explanation of the study, which was approved by the Ethics Committee of the Health Sciences School from the University of Brasilia. Written informed consent was obtained from each participant after a full explanation of the study, which was approved by the Ethics Committee of the Health Sciences School from the University of Brasilia.

\section{Anthropometric measurements and blood chemistry}

Height, weight, waist circumference (WC), systolic and diastolic blood pressures were measured and the results were averaged. The body mass index (BMI) was calculated by dividing the weight $(\mathrm{kg})$ by the height $(\mathrm{m})$ squared. After an overnight fast, with at least 12 hours, blood samples were taken for determination of laboratory parameters considered for this project: fasting glucose, total cholesterol and fractions, triglycerides. All samples from patients with MetS were analyzed by conventional methods only in the Clinical Laboratory of the University Hospital of Brasilia. The results of biochemical tests were analyzed according to cutoff points proposed by the NCEP/ATPIII criteria used for classification of MetS.

\section{rs1801282 genotyping}

A venous blood sample $(5 \mathrm{~mL})$ was obtained from peripheral venipuncture using disposable material 
and EDTA-containing tubes. Samples from MetS patients were collected at the University Hospital of Brasilia and, from volunteers, at Hemocentro Brasilia Foundation. DNA was extracted by the Chelex-100 method (21), and rs1801282 genotype assignments were conducted by allele-specific polymerase chain reaction.

Initially, each pair of primers for the rs1801282 polymorphism was used in PCR reactions with allele specific singleplex, in a final volume of $25 \mu \mathrm{l}$ containing $50 \mathrm{ng}$ template DNA; I ng of each primer (direct, general and reverse); Syber Green Rox qPCR Master Mix Thermo Scientific and 1x H2O Milli-Q qs (primers under request).

Amplifications were carried out in Step One Plus (Life Technologies ${ }^{\circledR}$ ), which was composed of the following: denaturation at $95^{\circ} \mathrm{C}$ for 10 minutes; followed by 40 cycles of 15 seconds denaturation at $95^{\circ} \mathrm{C}, 1$ minute at $60^{\circ} \mathrm{C}$ and melting curve $95^{\circ} \mathrm{C}$ for $15 \mathrm{sec}-$ onds; $60^{\circ} \mathrm{C} 1 \mathrm{~min}, 95^{\circ} \mathrm{C}$ for 15 seconds.

\section{Statistical analysis}

The categorical data were described as mean \pm standard deviation. Variables were analyzed using nonparametric analysis (Mann Whitney test and Fisher). HardyWeinberg equilibrium, differences in genotype and allele frequencies between MetS and general individuals were analyzed by using Pearson's $\chi^{2}$ test in GenAlex Program. All statistical tests were carried out using GraphPad Prism version 6.00 for Windows, GraphPad Software, San Diego, California, USA (www.graphpad. com). A p value $<0.05$ was considered statistically significant (two-tailed).

\section{RESULTS}

Genotyping was carried out for 333 unrelated subjects (154 MetS patients and 179 individuals from general population) from the University Hospital of Brasilia and from the Hemocentro Foundation of Brasilia, Brazil. In the MetS group, the mean age was $57.9 \pm$ 6.83 years and $67.53 \%$ were female. In the population group, the mean age was $49.33 \pm 4.22$ years, however the majority was male (67\%). Clinical characteristics of the individuals enrolled in the study are presented in tables 1 and 2 .

The genotyping results are summarized in table 3 . Deviation from the Hardy-Weinberg equilibrium was not seen in either the MetS $\left(\chi^{2}=0.462, \mathrm{df}=1, \mathrm{p}=\right.$
0.49 ) or the general group $\left(\chi^{2}=0.695, \mathrm{df}=1, \mathrm{p}=\right.$ $0.404)$. The genotype distribution of the rs 1801282 polymorphism for the MetS was 0.896 for the CC genotype and 0.103 for the CG genotype. For the general group, they were 0.888 and 0.112 , respectively. There were no GG genotypes in both groups. The biochemical and anthropometric results for all MetS subjects are shown in table 4 . No differences were seen in the mean values of age, height, weight, WC, BMI, plasma triglyceride, plasma total cholesterol, HDL and LDL cholesterol, as well as systolic and diastolic blood pressure among different genotypes, when we analyzed the MetS group individually (Table 5 ).

Table 1. Baseline characteristics of the metabolic syndrome subjects, University Hospital of Brasilia

\begin{tabular}{lc}
\hline $\mathbf{n}$ (154) & Mean $\mathbf{\text { S Standard deviation }}$ \\
\hline Gender (M/F) & $50 / 104$ \\
Age (years) & $57.9 \pm 6.83$ \\
Weight $(\mathrm{kg})$ & $79.87 \pm 16.29$ \\
Height $(\mathrm{cm})$ & $1.62 \pm 0.09$ \\
Waist circumference & $111.61 \pm 16.24$ \\
Systolic BP (mmHg) & $131.50 \pm 14.76$ \\
Diastolic BP (mmHg) & $84.09 \pm 7.97$ \\
BMI (kg/m²) & $30.73 \pm 6.57$ \\
FBS (mg/dL) & $152.81 \pm 73.66$ \\
Total-c (mg/dL) & $184.89 \pm 39.04$ \\
TGL (mg/dL) & $180.92 \pm 87.91$ \\
HDL-c (mg/dL) & $42.25 \pm 22.39$ \\
LDL-c (mg/dL) & $108.67 \pm 36.20$ \\
\hline
\end{tabular}

BP: blood pressure; BMI: body mass index; Total-c: total cholesterol; TGL: triglycerides; HDL-C: high density lipoprotein; LDL-C: low density lipoprotein; FBS: fasting glucose.

Table 2. Baseline characteristics of the volunteers subjects from the Hemocentro Foundation of Brasilia

\begin{tabular}{lc}
\hline $\mathbf{n}$ (179) & Mean \pm Standard deviation \\
\hline Gender (M/F) & $118 / 61$ \\
Age (years) & $49.33 \pm 4.22$ \\
Weight $(\mathrm{kg})$ & $77 \pm 16.5$ \\
Height $(\mathrm{cm})$ & $1.72 \pm 0.09$ \\
Systolic BP $(\mathrm{mmHg})$ & $124 \pm 10.99$ \\
Diastolic BP $(\mathrm{mmHg})$ & $82 \pm 10.83$ \\
BMl $\left(\mathrm{kg} / \mathrm{m}^{2}\right)$ & $26.45 \pm 4.32$ \\
$\mathrm{Hb} \mathrm{A1C}(\%)$ & $<6.5 \%{ }^{*}$ \\
\hline
\end{tabular}

BP: blood pressure; BMI: body mass index; Total-c: total cholesterol; TGL: triglycerides; HDL-C: high density lipoprotein; LDL-c: low density lipoprotein; Hb A1C: glycated hemoglobin.

* Criteria defined by the American Association of Diabetes and used by Hemocentro Foundation of Brasilia for screening type 2 diabetes mellitus. 
Table 3. Allelic frequency and genotypes distribution of studied population

\begin{tabular}{lccccc}
\hline \multirow{2}{*}{ Groups } & \multicolumn{2}{c}{$\begin{array}{c}\text { Allelic } \\
\text { frequencies (\%) }\end{array}$} & \multicolumn{3}{c}{$\begin{array}{c}\text { Genotypic } \\
\text { frequencies n (\%) }\end{array}$} \\
\cline { 2 - 6 } & C (Pro) & G (Ala) & CC (Pro/Pro) & CG (Pro/Ala) & GG (Ala/Ala) \\
\hline MetS & $146(94.8 \%)$ & $5.2(8 \%)$ & $138(89.61 \%)$ & $16(10.38 \%)$ & 0 \\
General population & $168(94.1 \%)$ & $5.9(11 \%)$ & $159(88.82 \%)$ & $20(11.17 \%)$ & 0 \\
\hline
\end{tabular}

MetS: metabolic syndrome.

Table 4. Comparison of biochemical, anthropometric and hemodynamic variables data of metabolic syndrome subjects between different groups of rs1801282 genotypes

\begin{tabular}{lccc}
\hline \multirow{2}{*}{$\begin{array}{l}\text { Variables } \\
\mathbf{n}=\mathbf{1 5 4}\end{array}$} & \multicolumn{2}{c}{ Pro12Ala polymorphism } & \\
\cline { 2 - 3 } & $\begin{array}{c}\text { Pro12Pro } \\
\mathbf{n}(\mathbf{1 3 8}) \mathbf{C C}\end{array}$ & $\begin{array}{c}\text { Pro12Ala } \\
\mathbf{n}(\mathbf{1 6}) \mathbf{C G}\end{array}$ & $\boldsymbol{p}$ \\
\hline Gender (M/F) & $46 / 92$ & $04 / 12$ & 0.3658 \\
Age (years) & $57.9 \pm 6.87$ & $58.12 \pm 6.69$ & 0.9238 \\
FBG (mg/dL) & $155.91 \pm 76.59$ & $126.31 \pm 30.83$ & 0.1562 \\
Total-c (mg/dL) & $183.71 \pm 39.26$ & $188.18 \pm 47.66$ & 0.4851 \\
TGL (mg/dL) & $184.22 \pm 90.16$ & $152.87 \pm 60.84$ & 0.2626 \\
HDL-c (mg/dL) & $42.45 \pm 23.44$ & $40.56 \pm 9.95$ & 0.4963 \\
LDL-c (mg/dL) & $107.49 \pm 35.08$ & $118.18 \pm 44.40$ & 0.3384 \\
BMI (kg/m²) & $30.94 \pm 6.63$ & $28.89 \pm 5.28$ & 0.2780 \\
Waist circumference & $111.93 \pm 16.14$ & $108.81 \pm 17.37$ & 0.4368 \\
Systolic BP (mmHg) & $131.67 \pm 15.11$ & $130 \pm 11.54$ & 0.8509 \\
Diastolic BP (mmHg) & $84.13 \pm 8.17$ & $83.75 \pm 6.19$ & 0.7248 \\
\hline
\end{tabular}

BP: blood pressure; BMI: body mass index; Total-c: total cholesterol; TGL: triglycerides; HDL-C: high density lipoprotein; LDL-C: low density lipoprotein; FBG: fasting blood glucose.

Table 5. Association of rs1801282 genotypes and the presence of metabolic syndrome components

\begin{tabular}{lccc}
\hline \multicolumn{1}{c}{ MetS components } & $\begin{array}{c}\text { Pro12Pro n } \\
\text { (\%) CC }\end{array}$ & $\begin{array}{c}\text { Pro12Ala n } \\
\text { (\%) CG }\end{array}$ & $\boldsymbol{p}$ \\
\hline $\mathrm{FBS} \geq 100(\mathrm{mg} / \mathrm{dL})$ & $133(96.37 \%)$ & $14(87.5 \%)$ & 0.1562 \\
$\mathrm{BP} \geq 130 / 85 \mathrm{mmHg}$ & $81(58.69 \%)$ & $7(43.75 \%)$ & 0.2925 \\
$\mathrm{TGL} \geq 150 \mathrm{mg} / \mathrm{dL})$ & $77(55.79 \%)$ & $8(50 \%)$ & 0.7919 \\
$\mathrm{HDL}-\mathrm{C}<40 \mathrm{mg} / \mathrm{dL}$ (men) & $24(17.39 \%)$ & $3(18.75 \%)$ & 0.1147 \\
$\mathrm{HDL}-\mathrm{C}<50 \mathrm{mg} / \mathrm{dL}$ (women) & $77(55.79 \%)$ & $8(50 \%)$ & 0.2251 \\
$\mathrm{WC} \geq 88 \mathrm{~cm}$ (women) & $89(64.49 \%)$ & $11(68.75 \%)$ & 0.3923 \\
$\mathrm{WC} \geq 102 \mathrm{~cm}$ (men) & $29(21.01 \%)$ & $3(18.75 \%)$ & 0.6292 \\
\hline
\end{tabular}

MetS: metabolic syndrome; BP: blood pressure; BMl: body mass index; Total-c: total cholesterol; TGL: triglycerides; HDL-c: high density lipoprotein; LDL-C: low density lipoprotein; FBS: fasting glucose; WC: waist circumference.

The analysis of the frequencies of the individual components of MetS also showed no significant difference among the genotypes (Table 6). To see if the effects of the polymorphisms were associated with hypertension $(\mathrm{BP}>130 / 85 \mathrm{mmHg})$, obese $\left(\mathrm{BMI}>30 \mathrm{~kg} / \mathrm{m}^{2}\right)$ or impaired fasting glucose (fasting glucose $>100 \mathrm{mg}$ / $\mathrm{dL}$ ), we divided the MetS group in three subgroups, but no statistically significant difference was found.

\section{DISCUSSION}

The observational of individual differences in the risk of developing MetS has led to an increased interest in genetic factors that might determine the susceptibility to insulin resistance, since it is the core physiopathological component of MetS (22-24). The identification of candidate genes for the syndrome has therefore been a major focus of research over the last decades, and it is expected that these findings will translate into better understanding of the physiopathology of MetS in addition to enabling the development of appropriate therapeutic and preventative strategies.

The initial description of the PPARG rs 1801282 polymorphism in patients with type 2 diabetes across diverse populations placed the gene as an attractive candidate in studies addressing genetic factors associated with metabolic disturbances. This was reinforced by well established role of PPAR $\gamma$ in regulating key aspects of energy balance, including adipocyte differenciation, lipogenesis and insulin action, in addition to the inflammatory response, angiogenesis and atherosclerosis (5). Many studies have subsequently investigated the association between $r s 1801282$ and the various individual components of MetS. Nevertheless, few of them have explored this association with the MetS as an entity. Our study is one of the few studies investigating this association, and is the first one addressing this issue in a Brazilian population.

The distribution of $r s 1801282$ polymorphism is quite wide, ranging from 0.630 to 0.956 for the CC genotype, from 0.015 to 0.300 for the $\mathrm{CG}$ genotype and from 0 to 0.067 for $\mathrm{GG}$. The frequency of the $\mathrm{C}$ allele ranges from 0.780 to 0.977 and that of the $\mathrm{G}$ allele varies from 0.023 to 0.220 for the G allele in an Iranian population (25). In the present study, we found that the frequency of the $\mathrm{C}$ allele was 0.95 and the frequency of the $\mathrm{G}$ allele was 0.05 in both the MetS group and the non-MetS group, and these results are in line with previous results observed in the general population. Indeed, our findings are close to the data from other previously published studies investigating diverse populations, such as the Chinese (26), Italian (27), French (28), African American (29), Korean 
Table 6. Comparison of biochemical, anthropometric and hemodynamic variables data of metabolic syndrome subjects between different groups of rs1801282 genotypes in three subdivided groups according to hypertension, diabetes and obesity

\begin{tabular}{|c|c|c|c|c|c|c|c|c|}
\hline \multirow{2}{*}{$\begin{array}{l}\text { MetS } \\
\text { components }\end{array}$} & \multicolumn{2}{|c|}{ All subjects with MetS } & \multicolumn{2}{|c|}{$\begin{array}{l}\text { Subjects with MetS } \\
\text { and hypertension } \\
\text { (BP } \geq 130 / 85 \mathrm{~mm} \mathrm{hg})\end{array}$} & \multicolumn{2}{|c|}{$\begin{array}{l}\text { Subjects with MetS and diabetes } \\
\text { (FBS } \geq 100 \mathrm{mg} / \mathrm{dL} \text { ) }\end{array}$} & \multicolumn{2}{|c|}{$\begin{array}{l}\text { Subjects with MetS and obesity } \\
\left(\text { (BMI } \geq 30 \mathrm{~kg} / \mathrm{m}^{2}\right)\end{array}$} \\
\hline & $\begin{array}{l}\text { PR012PRO } \\
\text { CC }(\mathrm{N}=138)\end{array}$ & $\begin{array}{l}\text { PR01 } \\
\text { CG (N }\end{array}$ & & $\begin{array}{l}\text { PR012 } \\
\text { CG (N : }\end{array}$ & & & & \\
\hline $\begin{array}{l}\text { Systolic BP } \\
(\mathrm{mmHg})\end{array}$ & $131.67 \pm 15.11$ & $130 \pm 11.54$ & $0.72 \pm 12.68$ & 140 & $1.66 \pm 15.28$ & $130.71 \pm 12.06$ & $132.59 \pm 14.36$ & $125.71 \pm 9.75$ \\
\hline $\begin{array}{l}\text { Diastolic BP } \\
(\mathrm{mmHg})\end{array}$ & 7 & & U & & & & .16 & 87 \\
\hline $\mathrm{FBS}(\mathrm{mg} / \mathrm{dL})$ & $155.91 \pm 76.59$ & $126.31 \pm 30.83$ & $158.02 \pm 87.87$ & $127.85 \pm 29.57$ & $158.35=$ & $131.64 \pm 29.15$ & 143.17 & $131.71 \pm 40.43$ \\
\hline $\mathrm{TGL}(\mathrm{mg} / \mathrm{dL})$ & $184.22 \pm 90.16$ & $152.87 \pm 60.84$ & $191.27 \pm 88.11$ & $174.42 \pm 63.80$ & $185.54 \pm 90.72$ & $163.44 \pm 57.46$ & $177.44 \pm 87.63$ & $139.14 \pm$ \\
\hline HDL-c (mg/dL) & $42.45 \pm 23.44$ & $40.56 \pm 9.95$ & $43.20 \pm 28.66$ & $38.71 \pm 8.55$ & $42.66 \pm 23.82$ & $39.28 \pm 10.01$ & $39.73 \pm 11.14$ & $42.14 \pm 7.71$ \\
\hline $\begin{array}{l}\text { Waist } \\
\text { circumference }\end{array}$ & $111.93 \pm 16.14$ & $108.81 \pm 17.37$ & $112.50 \pm 15.53$ & $105.71 \pm 17.19$ & $111.56 \pm 15.61$ & $107.28 \pm 15.10$ & $119.72 \pm 14.56$ & $123.71 \pm 14.04$ \\
\hline
\end{tabular}

MetS: metabolic syndrome; HDL-c: high density lipoprotein; BP: blood pressure; BMI: body mass index; TGL: triglycerides.

P-value and the values given refer to the crude analysis (i.e, not adjusted for age and sex).

(15), Scotish (30), German (31), Finn (28) and Hispanic (32) populations. Additionally, in the first five populations listed above, the Alal2Ala genotype was not found, reinforcing the rarity of this variant worldwide.

Similar to other studies, the association between the rs1801282 polymorphism and MetS risk was not found in this small sample from Brasilia population. Moreover, this variant was not associated with any of the investigated biochemical, anthropometric or hemodynamic variables among the MetS group. A French population-based study involving 1,155 individuals, including 279 men and women with MetS defined according to NCEP/ATPIII, concluded that none of the polymorphisms studied, including rs1801282, was associated with MetS risk (8). A small study involving 253 Korean women diagnosed with MetS (also defined by NCEP/ATPIII recommendations) did not find any association of this syndrome with the genotypes analyzed. There were also no differences between BMI, blood pressure, fasting glucose levels, fasting insulin levels and insulin resistance defined by the homeostatic model assessment in Ala carriers when compared with dominant Pro allele (15).

Rooki and cols. investigated the association between two PPARG genotypes polymorphisms (rs3856806 and rs1801282) and their haplotypes in patients with MetS in 340 individuals from Iran (175 patients with MetS and 165 healthy controls), and found a significant difference between the frequency of $r s 3856806$ frequencies among individuals with MetS and healthy controls, although no association was found between the frequency of $r s 1801282$ and the occurrence of MetS (33). Yang and cols. also investigated the $r s 3856806$ and $r s 1801282$ polymorphisms in 423 Chinese individuals with MetS and found that only rs3856 concluded that only the first one was associated with MetS (34). Another Chinese study with 792 subject from Beijing analyzed the correlations between the occurrence of insulin resistance and MetS and the PPARG variants rs1801282 and rs3856806, and found both polymorphisms were associated with insulin results, but not with the components of MetS (35). Finally, results from a recent meta-analysis indicated that the $r s 1801282$ polymorphism might not be related to MetS as an entity, but could affect the risk of the individual components of this syndrome (14). In our study, there was no association between the frequency of the rs 1801282 polymorphism and either MetS as an entity or its individual components.

In conclusion, the rs 1801282 polymorphism in PPARG does not seem to be involved with MetS risk in a Brazilian population. We emphasize that a limitation of our study is the relatively small sample size. Thus, further studies with larger population bases are needed to clarify this issue.

Disclosure: no potential conflict of interest relevant to this article was reported.

\section{REFERENCES}

1. Kassi E, Pervanidou P, Kaltsas G, Chrousos G. Metabolic syndrome: definitions and controversies. BMC Med. 2911;9:48.

2. Grundy SM. Metabolic syndrome pandemic. ArteriosclerThromb Vasc Biol. 2008;28(4):629-36.

3. Reaven GM. Banting lecture 1988. Role of insulin resistance in human disease. Diabetes. 1988;37(12):1595-607. 
4. Bruce KD, Byrne CD. The metabolic syndrome: common origins of a multifactorial disorder. Postgrad Med J. 2009;85(1009):614-21.

5. Azhar S. Peroxisome proliferator-activated receptors, metabolic syndrome and cardiovascular disease. Future Cardiol. 2010;6(5):657-91.

6. Yen CJ, Beamer BA, Negri C, Silver K, Brown KA, Yarnall DP, et al. Molecular scanning of the human peroxisome proliferator activated receptor gamma (hPPAR gamma) gene in diabetic Caucasians: identification of a Pro12Ala PPAR gamma 2 missense mutation. Biochem Biophys Res Commun. 1997;241(2):270-4.

7. Stumvoll $M$, Häring $H$. The peroxisome proliferator-activated receptor-gamma2 Pro12Ala polymorphism. Diabetes. 2002;51(8):2341-7.

8. Meirhaeghe A, Cottel D, Amouyel P, Dallongeville J. Association between peroxisome proliferator-activated receptor gamma haplotypes and the metabolic syndrome in French men and women. Diabetes. 2005;54(10):3043-8.

9. Schäffler A, Barth N, Schmitz G, Zietz B, Palitzsch KD, Schölmerich J. Frequency and significance of Pro12Ala and Pro115GIn polymorphism in gene for peroxisome proliferation-activated receptor-gamma regarding metabolic parameters in a Caucasian cohort. Endocrine. 2001;14(3):369-73.

10. Zhou TB, Guo XF, Yin SS. Association of peroxisome proliferatoractivated receptor $\gamma$ Pro12Ala gene polymorphism with type $2 \mathrm{di}-$ abetic nephropathy risk in Caucasian population. J Recept Signal Transduct Res. 2014;34(3):180-4.

11. Deeb SS, Fajas L, Nemoto M, Pihlajamäki J, Mykkänen L, Kuusisto J, et al. A Pro12Ala substitution in PPARgamma2 associated with decreased receptor activity, lower body mass index and improved insulin sensitivity. Nat Genet. 1998;20(3):284-7.

12. González Sánchez JL, Serrano Ríos M, Fernández Perez C, Laakso M, Martínez Larrad MT. Effect of the Pro12Ala polymorphism of the peroxisome proliferator-activated receptor gamma-2 gene on adiposity, insulin sensitivity and lipid profile in the Spanish population. Eur J Endocrinol. 2002;147(4):495-501.

13. Tellechea ML, Aranguren F, Pérez MS, Cerrone GE, Frechtel GD, Taverna MJ. Pro12Ala polymorphism of the peroxisome proliferatoractivated receptor-gamma gene is associated with metabolic syndrome and surrogate measures of insulin resistance in healthy men: interaction with smoking status. Circ J. 2009;73(11):2118-24.

14. Zhang R, Wang J, Yang R, Sun J, Chen R, Luo H, et al. Effects of Pro12Ala polymorphism in peroxisome proliferator-activated receptor-gamma2 gene on metabolic syndrome risk: a meta-analysis. Gene. 2014; 535(1):79-87.

15. Rhee EJ, Oh KW, LeeWY, Kim SY, Oh ES, Baek KH, et al. Effects of two common polymorphisms of peroxisome proliferator-activated receptor-gamma gene on metabolic syndrome. Arch Med Res. 2006;37(1):86-94.

16. Montagnana M, Fava C, Nilsson PM, Engström G, Hedblad B, Lippi $\mathrm{G}$, et al. The Pro12Ala polymorphism of the PPARG gene is not associated with the metabolic syndrome in an urban population of middle-aged Swedish individuals. Diabet Med. 2008;25(8):902-8.

17. National Cholesterol Education Program (NCEP) Expert Panel on Detection, Evaluation, and Treatment of High Blood Cholesterol in Adults (Adult Treatment Panel III). Third Report of the National Cholesterol Education Program (NCEP) Expert Panel on Detection, Evaluation, and Treatment of High Blood Cholesterol in Adults (Adult Treatment Panel III) final report. Circulation. 2002;106(25):3143-421.

18. American Diabetes Association. Diagnosis and classification of diabetes mellitus. Diabetes Care. 2013;36.

19. Eckel RH, Jakicic JM, Ard JD, de Jesus JM, Houston Miller N, Hubbard VS, et al. 2013 AHA / ACC orientação sobre gestão de estilo de vida para reduzir o risco cardiovascular: um relatório do American College of Cardiology Task Force Association / American Heart on Practice Guidelines. Circulation. 2014;129(25 Suppl 2):S76-99.
20. WHO. BMI classification. 2008b 2008 [cited 2014. 13 out]. Available from: <http://apps.who.int/bmi/index.jsp?introPage=intro_3. html>.

21. Miller SA, Dykes DD, Polesky HF. A simple salting out procedure for extracting DNA from human nucleated cells. Nucleic Acids Res. 1988;16(3):1215.

22. Stančáková A, Laakso M. Genetics of metabolic syndrome. Rev Endocr Metab Disord. 2014;15(4):243-52.

23. Kluge R, Scherneck $S$, Schürmann A, Joost HG. Pathophysiology and genetics of obesity and diabetes in the New Zealand obese mouse: a model of the human metabolic syndrome. Methods Mol Biol. 2012;933:59-73.

24. Monda KL, North KE, Hunt SC, Rao DC, Province MA, Kraja AT. The genetics of obesity and the metabolic syndrome. Endocr Metab Immune Disord Drug Targets. 2010;10(2):86-108.

25. Rooki H, Haerian MS, Azimzadeh P, Ebrahimi M, Mirhafez R, Ferns $\mathrm{G}$, et al. Distribution and genotype frequency of the C1431T and pro12ala polymorphisms of the peroxisome proliferator activator receptor gamma gene in an Iranian population. Indian J Hum Genet. 2013;19(4):423-9.

26. Li LL, Ma XL, Ran JX, Sun XF, Xu LM, Ren J, et al. Genetic polymorphism of peroxisome proliferator-activated receptor-gamma 2 Pro12Ala on ethnic susceptibility to diabetes in Uygur, Kazak and Han subjects. Clin Exp Pharmacol Physiol. 2008;35(2):187-91.

27. Orio F Jr, Matarese G, Di Biase S, Palomba S, Labella D, Sanna V, et al. E Exon 6 and 2 peroxisome proliferator-activated receptorgamma polymorphisms in polycystic ovary syndrome. J Clin Endocrinol Metab. 2003;88(12):5887-92.

28. Valve R, Sivenius K, Miettinen R, Pihlajamäki J, Rissanen A, Deeb SS, et al. Two polymorphisms in the peroxisome proliferator-activated receptor-gamma gene are associated with severe overweight among obese women. J Clin Endocrinol Metab. 1999;84(10):3708-12.

29. Kao WH, Coresh J, Shuldiner AR, Boerwinkle E, Bray MS, Brancati FL; Atherosclerosis Risk in Communities Study. Pro12Ala of the peroxisome proliferator-activated receptor-gamma2 gene is associated with lower serum insulin levels in nonobese African Americans: the Atherosclerosis Risk in Communities Study. Diabetes. 2003;52(6):1568-72.

30. Doney AS, Fischer B, Cecil JE, Boylan K, McGuigan FE, Ralston $\mathrm{SH}$, et al. Association of the Pro12Ala and C1431T variants of PPARG and their haplotypes with susceptibility to Type 2 diabetes. Diabetologia. 2004;47(3):555-8.

31. Mössner R, Meyer P, Jankowski F, König IR, Krüger U, Kammerer $\mathrm{S}$, et al. Variations in the peroxisome proliferator-activated receptor-gamma gene and melanoma risk. Cancer Lett. 2007;246(12):218-23.

32. Moffett SP, Feingold E, Barmada MM, Damcott CM, Marshall JA, Hamman RF, et al. The C161-->T polymorphism in peroxisome proliferator-activated receptor gamma, but not $\mathrm{P} 12 \mathrm{~A}$, is associated with insulin resistance in Hispanic and non-Hispanic white women: evidence for another functional variant in peroxisome proliferator-activated receptor gamma. Metabolism. 2005;54(11):1552-6.

33. Rooki H, Haerian MS, Azimzadeh $P$, Mirhafez R, Ebrahimi M, Ferns G, et al. A Associations between C1431T and Pro12Ala variants of PPAR $\gamma$ gene and their haplotypes with susceptibility to metabolic syndrome in an Iranian population. Mol Biol Rep. 2014;41(5):3127-33.

34. Yang LL, Hua Q, Liu RK, Yang Z. Association between two common polymorphisms of PPARgamma gene and metabolic syndrome families in a Chinese population. Arch Med Res. 2009;40(2):89-96.

35. Dongxia L, Qi H, Lisong L, Jincheng G. Association of peroxisome proliferator-activated receptorgamma gene Pro12Ala and C161T polymorphisms with metabolic syndrome. Circ J. 2008;72(4):551-7. 